\title{
Figures, Tables, and Text Boxes
}

\section{FIGURES}

1. Aggregate Religiosity Index (ARI), United States, 1952-2005

2. Rate of religious service attendance by race, United States, 1972-2018

3. Rate of prayer by race, United States, 1983-2018

4. Trends in Latinx religious affiliation, United States, 2000-2018

5. Weekly rate of religious service attendance by education level, United States, 1972-2018

6. Daily rate of prayer by education level, United States, 1983-2018

7. Proportion of population with no religious affiliation by gender, United States, 1972-2018

8. Weekly rate of religious service attendance by gender, United States, 1972-2018

9. Proportion with no religious affiliation by combined race, education, and gender groups, United States, 1972-2018

10. Average rates of religious service attendance by combined race, education, and gender groups, United States, 1972-2018 
11. Average rates of prayer by combined race, education, and gender groups, United States, 1983-2018

12. Percentage of women affiliated with religious traditions in 1977 , 2018, and predicted levels in 2018 if demographic characteristic shown remained at 1977 levels, United States

13. Percentage of men affiliated with religious traditions in 1977, 2018, and predicted levels in 2018 if demographic characteristic shown remained at 1977 levels, United States

14. Increasing ethnic diversity in predominantly White congregations, United States

15. Sample headlines following the 2016 election of Donald Trump

16. Proportion of population with no religious preference by year and political views, United States, 1974-2012

17. Origins of the US immigrant population, 1960-2015

18. Correlations between religious service attendance and social conservatism, United States

TAB LES

1. Trends in religious affiliation, United States, 1972-2016

2. Percentage not affiliated with any religion by age group and survey year, United States, 1976-2016

3. Predicted change over time in probability of religious service attendance in a given week if certain demographic changes had not occurred, United States, 1977-2018

4. Predicted change over time in probability of praying in a given day if certain demographic changes had not occurred, United States, 1977-2018 
B OXES

1. Social definitions of religion 4

2. Race and religion in the United States: A historical perspective 35

3. Gender, religiosity, and youth/young adults 45

4. Cohort vs. generation 61

5. Religious composition of countries around the world 82

6. Geographic variation 85

7. Exploring congregational data 99

8. Personal religion and politics 105

$\begin{array}{ll}\text { 9. } & \text { Religion in public blog } \\ & 120\end{array}$ 
